\title{
Thermal Upgrading of Nickeliferous Pyrrhotite Tailings for the Recovery of Nickel in the Form of Ferronickel Alloy
}

\author{
DAWEI YU, FENG LIU, JIAJING ZHANG, and MANSOOR BARATI
}

\begin{abstract}
Production of ferronickel alloy by thermal treatment of nickeliferous pyrrhotite (Pyrr) tailings was studied by both thermodynamic assessment and experimentation. It was demonstrated that $\mathrm{Ni}$ can be extracted from Pyrr by increasing the $\mathrm{Fe} / \mathrm{S}$ ratio of the material, which was achieved by either partial oxidation of Pyrr followed by $\mathrm{H}_{2}$ reduction or in situ generation of metallic $\mathrm{Fe}$ from the reduction of magnetite by petroleum coke pre-mixed with Pyrr. Examination of the samples produced from thermal treatment at $1173 \mathrm{~K}$ demonstrated that both approaches were effective in generating ferronickel, although the size of the particles was suboptimal for subsequent separation. Increasing the ferronickel particle size could be achieved by a smelting step at $1473 \mathrm{~K}$, forming a sulfur-deficient molten matte. Slow cooling of the molten matte resulted in precipitation, settling, and growth of ferronickel alloy particles.
\end{abstract}

https://doi.org/10.1007/s11663-019-01646-5

(C) The Minerals, Metals \& Materials Society and ASM International 2019

\section{INTRODUCTION}

PYRRhotite (Pyrr, $\mathrm{Fe}_{1-x} \mathrm{~S}, x=0$ to 0.125 ) is ubiquitous in $\mathrm{Ni}-\mathrm{Cu}$ sulfide ore deposits. In the beneficiation of Ni sulfide ores, the main Ni-bearing mineral, i.e., pentlandite $(\mathrm{Fe}, \mathrm{Ni})_{9} \mathrm{~S}_{8}$, is recovered into the $\mathrm{Ni}$ concentrate while the bulk of the sulfidic constituents being Pyrr is rejected as tailings to improve smelting capacity and minimize $\mathrm{SO}_{2}$ emissions. ${ }^{[1]}$ It has been recognized that, for the Ni sulfide ores in the Sudbury region of Ontario, Canada, appreciable amounts of pentlandite occurs as micro-sized "flames" finely disseminated in the Pyrr matrix ${ }^{[2]}$; as a consequence, this part of pentlandite together with Pyrr inevitably reports to the tailing stream. On the other hand, the nonstoichiometric Pyrr found in Sudbury has a dissolved Ni content in the range of 0.6 to 0.8 pct $\mathrm{Ni}$, which represents more than half of the total $\mathrm{Ni}$ value contained in the Pyrr tailings. ${ }^{[3]}$ Estimates show that in Sudbury about 75 to $100 \mathrm{Mt}$ Pyrr on a dry basis has been accumulated, and fresh Pyrr tailings are being produced

DAWEI YU is with the School of Metallurgy and Environment, Central South University, 932 Lushan South Road, Changsha, Hunan 410083 P. R. China and also with the Department of Materials Science and Engineering, University of Toronto, 184 College Street, Toronto, ON M5S 3E4, Canada. Contact e-mail: dawei.yu@csu.edu.cn FENG LIU, JIAJING ZHANG, and MANSOOR BARATI are with the Department of Materials Science and Engineering, University of Toronto.

Manuscript submitted March 19, 2019.

Article published online July 23, 2019. at a rate of up to $\sim 5000$ tpd. $^{[4]}$ Given these facts, Sudbury Pyrr tailings may be regarded as a significant $\mathrm{Ni}$ resource, and a process for the recovery of $\mathrm{Ni}$ and mitigation of tailings has been of interest. Such a process could potentially be applied to Pyrr of other mines where there has been reports of high Ni contents, such as 2 to 3 pct Ni in Norilsk, Russia, ${ }^{[5-7]}$ and 1 to 2 pct Ni in Jinchuan, China. ${ }^{[7,8]}$

The last attempt to commercially process Sudbury Pyrr tailings for value recovery was ended by Vale (formerly known as INCO) in 1991 with the shutdown of roasters. ${ }^{[9]}$ At present, impounding Pyrr tailings is practiced, which reportedly is the most effective measure to prevent the occurrence of acid mine drainage (AMD).$^{[10]}$ However, subaqueous deposition of Pyrr tailings requires high maintenance costs, and the sulfide oxidation in Pyrr-rich tailing impoundments is an ongoing risk. ${ }^{[11]}$ In this regard, the development of economically sound and environmentally friendly technologies is still needed for processing of Sudbury Pyrr tailings to mitigate their long-term environmental impact.

A thermal upgrading process to concentrate $\mathrm{Ni}$ in an alloy phase followed by magnetic separation was first studied by Vale in the 1970s. ${ }^{[12,13]}$ The basic principle behind this process has been discussed in a previous publication. ${ }^{[14]}$ As shown in the $\mathrm{Fe}-\mathrm{Ni}-\mathrm{S}$ isotherm (Figure 1), at $1173 \mathrm{~K}$, a monosulfide solid solution (mss) exists between $\mathrm{Fe}_{1-x} \mathrm{~S}$ and $\mathrm{Ni}_{1-x} \mathrm{~S}$, and the Fe-rich portion of this ternary system is dominated by a twophase assemblage " $\gamma+$ mss". A typical composition of Sudbury Pyrr tailing ${ }^{[15]}$ indicated by a star symbol in Figure 1, is found to be located within the area of mss 


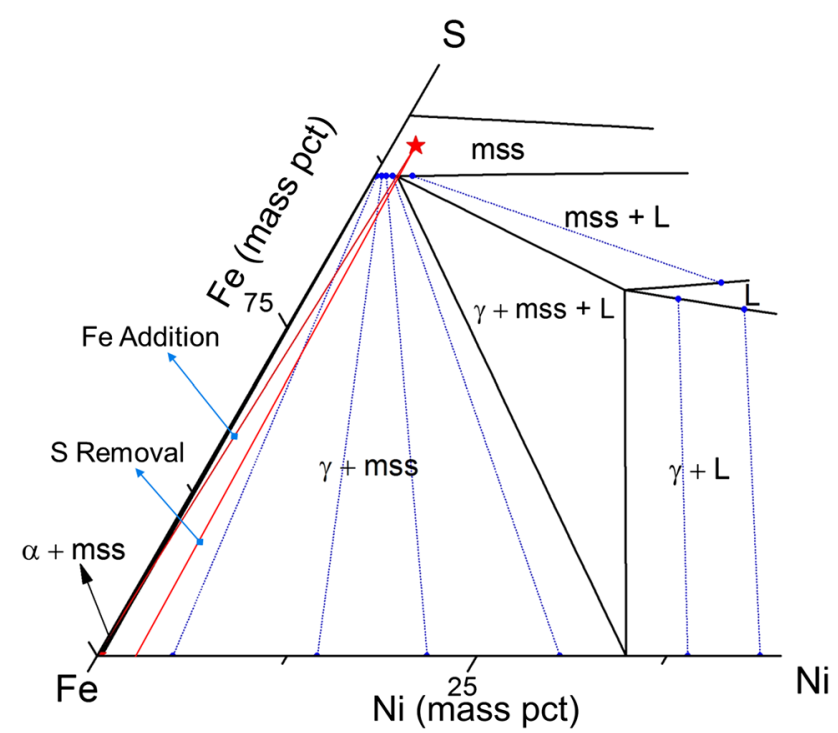

Fig. 1-Fe-rich portion of the Fe-Ni-S system at $1173 \mathrm{~K}$, illustrating the basic principle of the thermal upgrading process. ${ }^{[16]}$

and close to the Fe-S side. The thermal upgrading process can be viewed as the change in phase associations from a one-phase region "mss" to a two-phase region or even a three-phase region "alloy + mss" as a result of the modification in the overall composition. This can be achieved by adding iron into and/or removing sulfur from the Pyrr lattice, thereby converting nickeliferous Pyrr to a mixture of FeNi alloy and sulfide phases. The possibility of extracting $\mathrm{Ni}$ from nickeliferous Pyrr, thus, relies on its significantly higher solubility in $\gamma$ than in mss, which is thermodynamically determined by the position of tie lines in " $\gamma+$ mss". Therefore, the main function of the thermal upgrading process would be to increase the $\mathrm{Fe} / \mathrm{S}$ ratio of the system to approach stoichiometric iron sulfide, FeS.

In this study, a thermodynamic assessment of the thermal upgrading process was performed using the thermochemical software FactSage ${ }^{\top \mathrm{M}}{ }^{[16]}$ Narrowing down the range of favorable conditions, two experimental approaches were then employed to increase the $\mathrm{Fe} / \mathrm{S}$ molar ratio of the Pyrr tailings. The first approach was the removal of sulfur by partial oxidation of Pyrr with air. Oxidation inevitably introduces oxygen in the form of iron oxides, necessitating the subsequent reduction of the oxide. Hydrogen $\left(\mathrm{H}_{2}\right)$ was used as the reductant for this reduction. The second approach was the addition of iron (Figure 1), which was realized by mixing Pyrr with magnetite $\left(\mathrm{Fe}_{3} \mathrm{O}_{4}\right)$ and a carbonaceous reductant. During the pyrometallurgical treatment process, metallic $\mathrm{Fe}$ was formed in situ from the direct reduction of $\mathrm{Fe}_{3} \mathrm{O}_{4}$ with carbon. The overall objectives of this study are (1) to gain a better understanding of the thermal upgrading process from the perspectives of both reaction mechanisms and kinetics, and (2) to promote the growth of ferronickel alloy particles, facilitating their subsequent separation from the residual sulfides.

\section{MATERIALS AND METHODS}

\section{A. Materials}

The chemical composition of the as-received Pyrr tailing (dry-basis) is listed in Table I. As seen from its sulfur content, the Pyrr tailing is pure, containing 0.85 mass pet $\mathrm{Ni}$ with minor amounts of impurities such as $\mathrm{Mg}, \mathrm{Al}$, and $\mathrm{Co}$. The particle size distribution of the as-received Pyrr tailing, determined by laser scattering, is shown in Figure 2(a) with a median particle size (i.e., $d(0.5))$ of $26.1 \mu \mathrm{m}$. Figure $2(\mathrm{~b})$ is the scanning electron microscope (SEM) image of the cross section of the Pyrr tailing. Energy-dispersive spectrometry (EDS) analysis on the cross section indicates the presence of minor amounts of magnetite particles, which explains the fact that the overall molar ratio of Fe:S is slightly higher than unity (Table I). The Pyrr tailing was initially dried at $378 \mathrm{~K}$ for 2 hours before use in the study.

Magnetite used in the study was in a fine powder form with 90 pct below $5.3 \mu \mathrm{m}$. Petroleum coke powder with a fixed carbon content of 85.1 mass pct was ground using a ball mill, and the fraction passing $38 \mu \mathrm{m}$ sieve was used as the carbonaceous reductant.

\section{B. Methods}

\section{Thermodynamic evaluation}

Equilib module of the thermochemical software FactSage $^{\text {тм[16] }}$ was employed to evaluate the influence of two most important parameters (i.e., sulfur-to-metal ratio and temperature) on the phase evolution and compositions of the Fe-Ni-S system. Databases of FactPS and FTmisc were chosen for the evaluations. The first evaluation was performed by varying the molar ratio of $\mathrm{S} /(\mathrm{Fe}+\mathrm{Ni})$ in the range of 0.25 to 1.0 at a temperature of $1173 \mathrm{~K}$, while maintaining a constant Ni:Fe molar ratio of 0.0129 , which is the same as that of the Pyrr tailing used in the investigation. The second evaluation was conducted at temperatures ranging from $773 \mathrm{~K}$ to $1473 \mathrm{~K}$ at a $\mathrm{S} /(\mathrm{Fe}+\mathrm{Ni})$ molar ratio of 0.7 and a $\mathrm{Ni}: \mathrm{Fe}$ molar ratio of 0.0129 , to study the influence of temperature on the formation of metallic phase when sulfur is deficient in the Fe-Ni-S system.

\section{Thermogravimetric analysis}

Thermogravimetric analysis (TGA) and differential thermal analysis (DTA) were performed using a Setaram TG-DTA 92 unit (SETARAM Inc., Newark, CA), which was coupled with a gas analyzer (ABB EL3020) for continuous analysis of the $\mathrm{CO}, \mathrm{CO}_{2}$, and/or $\mathrm{SO}_{2}$ concentrations in the offgas. To determine the appropriate temperature for the partial oxidation of Pyrr, it is of great importance to first determine the oxidative reaction sequence of Pyrr by air as a function of reaction temperature. This was examined by heating a $10-\mathrm{mg}$ Pyrr sample, which was placed loosely inside an alumina crucible (I.D. $7.2 \mathrm{~mm}$ ) in the TGA unit at a heating rate of $10 \mathrm{~K} / \mathrm{min}$ to $1283 \mathrm{~K}$ with an air flowrate of $500 \mathrm{~mL} /$ min. Individual samples were collected after reaching a particular intermediate temperature by moving the sample to the cold end of the TGA heating chamber, 
thereby allowing the sample to be air-quenched. These intermediate samples were subjected to both SEM and $\mathrm{X}$-ray powder diffraction (XRD) analyses.

Sequential partial oxidation-reduction of the Pyrr sample $(10 \mathrm{mg})$ was performed by initially heating in an Ar flow of $500 \mathrm{~mL} / \mathrm{min}$ at $15 \mathrm{~K} / \mathrm{min}$ to the predetermined oxidation temperature, and holding at this temperature for $15 \mathrm{~min}$. During this dwelling time, purging gas was switched to air (extra dry, $500 \mathrm{~mL} / \mathrm{min}$ ) for a short time (15 or 25 seconds), achieving partial oxidation. The sample was subsequently heated to a higher temperature of $1173 \mathrm{~K}$ in $\mathrm{Ar}$ (grade $5.0 \mathrm{~N}$, $500 \mathrm{~mL} / \mathrm{min}$ ) at $15 \mathrm{~K} / \mathrm{min}$, and holding at this temperature for 2 hours before cooling to room temperature. During this dwelling time, purging gas was switched to a $\mathrm{N}_{2}-15 \mathrm{vol}$ pct $\mathrm{H}_{2}$ gas for a determined period of time, allowing subsequent reduction. After cooling in Ar to room temperature, the samples were analyzed by SEM/ EDS.

Heating of the mixtures of Pyrr, magnetite, and petroleum coke was conducted using a sample pellet. Pyrr, magnetite, and petroleum coke were mixed thoroughly at a mass ratio of $3.0: 1.0: 0.4$, resulting in the pellet composition of 68.2 mass pet Pyrr, 22.7 mass pet magnetite, and 9.1 mass pct petroleum coke. A sample mixture of typically $30 \mathrm{mg}$ was placed inside a $10-\mathrm{mm}$ die set and pressed to form a pellet using a hydraulic press with a pressure of approximately $600 \mathrm{MPa}$. The pellet was broken to form three to five pieces of fragments before placing into the alumina crucible (I.D. $7.2 \mathrm{~mm}$ ) for thermal treatment in the TG-DTA unit, with a continuous Ar flow of $500 \mathrm{~mL} / \mathrm{min}$.

Table I. Elemental Composition (Mass Percent) of the Pyrr Tailing (Dry-Basis)

\begin{tabular}{lccccccc}
\hline Elements & $\mathrm{Fe}$ & $\mathrm{S}$ & $\mathrm{Ni}$ & $\mathrm{Cu}$ & $\mathrm{Mg}$ & $\mathrm{Al}$ & $\mathrm{Co}$ \\
\hline Mass Percent & 62.86 & 35.66 & 0.85 & 0.16 & 0.15 & 0.03 & 0.01 \\
\hline
\end{tabular}

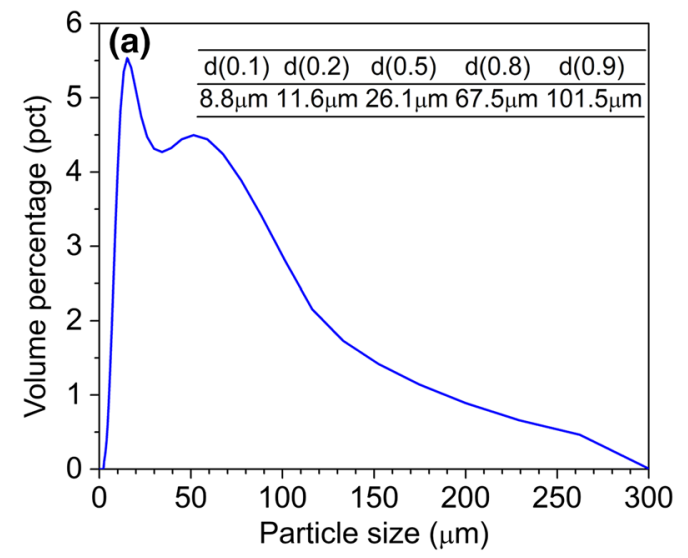

In all the TGA experiments, the microbalance chamber of the unit was continuously purged with an isolating $\mathrm{Ar}$ gas stream of $7 \mathrm{~mL} / \mathrm{min}$ to protect the microbalance. This Ar gas subsequently enters the heating chamber, causing slight dilution of the main reaction gas.

\section{SEM and XRD analyses}

Polished sections of the thermally treated samples were prepared by mounting the samples into epoxy resin, which were subsequently ground using silicon carbide papers in a dry condition and polished using the mineral oil-based, 1- $\mu \mathrm{m}$ diamond suspension, thereby preventing the possible loss of water-soluble phases (e.g., sulphates) from the sample during sample preparation. Polished sections were examined by SEM (JEOL, JSM-840), complemented by an EDS (PGT/AAT), using an accelerating voltage of $20 \mathrm{kV}$. For XRD analysis, the samples were manually ground using a mortar and pestle, which were then mixed with acetone on a single crystalline silica slide for analysis. XRD spectra were then acquired on a Philips PW2273/20 diffractometer using $\mathrm{Cu} \mathrm{K} \alpha$ radiation.

\section{RESULTS AND DISCUSSION}

\section{A. Thermodynamic Evaluation}

According to the Fe-Ni-S isotherm at $1173 \mathrm{~K}$ shown in Figure 1, formation of the $\gamma$ alloy phase is dependent on the degree of sulfur deficiency in terms of the sulfurto-metal $(\mathrm{Fe}+\mathrm{Ni})$ molar ratio. Figure 3(a) shows the results of thermodynamic evaluation with the $\mathrm{Fe} / \mathrm{S}$ ratio as the variable. In the figure, $\frac{\mathrm{Ni} \text { in } \gamma}{\mathrm{Ni}-\text { total }}$ represents the Ni recovery into the $\gamma$ phase, $\frac{\gamma}{\gamma+\text { Pyrr }}$ represents the mass pct of the $\gamma$ phase in the product after reaching thermodynamic equilibrium, and $\frac{\mathrm{Ni}}{\mathrm{Fe}+\mathrm{Ni}}$ in $\gamma$ represents the Ni concentration (wt pct) in the $\gamma$ phase (i.e., highest

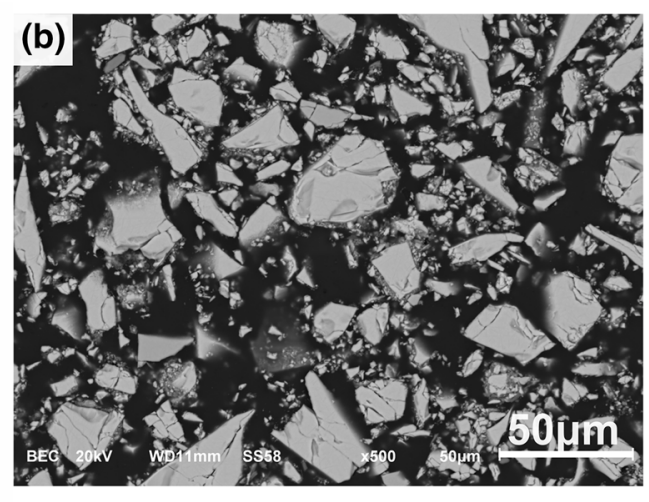

Fig. 2-Particle size distribution (a) and cross-sectional microscopical image (b) of the Pyrr tailing. 


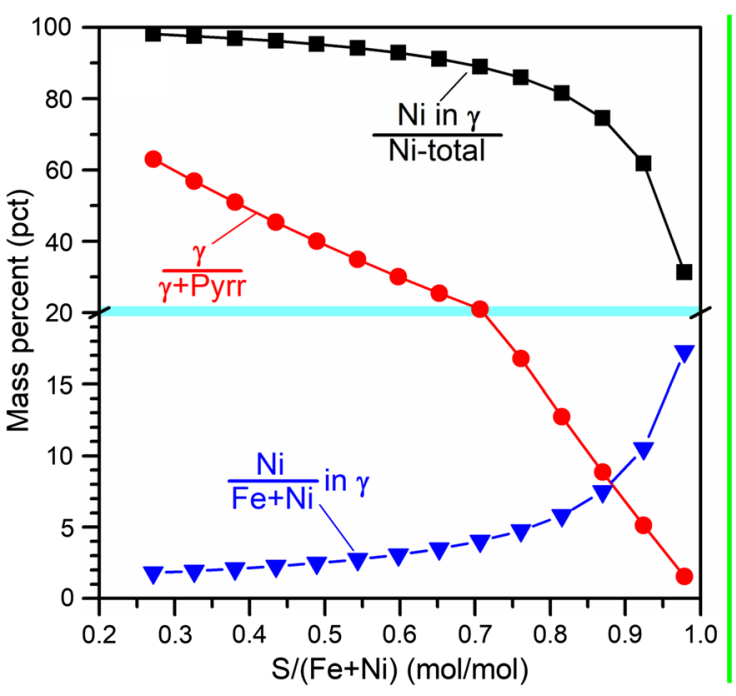

(a)

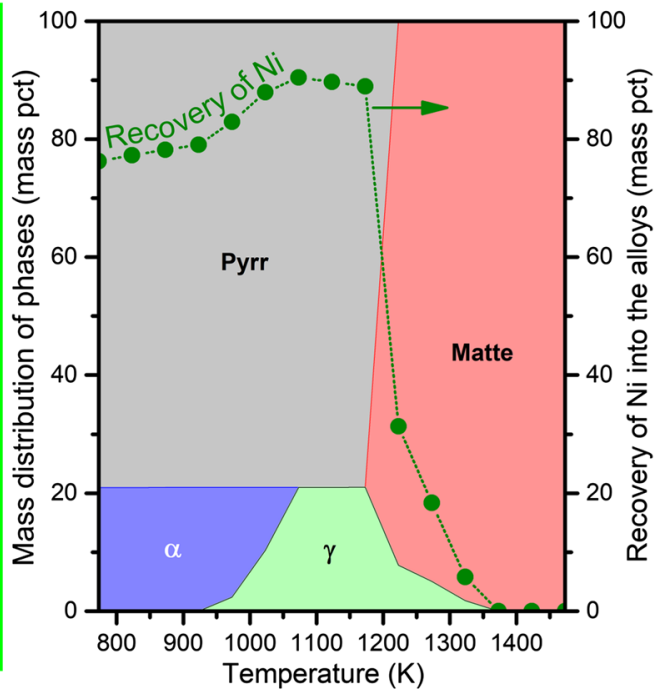

(b)

Fig. 3-FactSage ${ }^{\mathrm{TM}}$ simulation on $(a)$ the effect of the molar ratio of $\mathrm{S} /(\mathrm{Fe}+\mathrm{Ni})$ on the formation of $\gamma$ alloy phase at $1173 \mathrm{~K}$. (The horizontal line indicates the change in the scale of $y$-axis.) (b) The effect of temperature on the formation of various phases and the degree of Ni recovery into the alloys.

possible Ni grade in the FeNi product). As seen, Ni recovery into the $\gamma$ phase can be increased with a higher sulfur deficiency, which will result in a lower $\mathrm{Ni}$ concentration in the $\gamma$ phase. For example, by reducing the sulfur-to-metal ratio from 0.92 to $0.76, \mathrm{Ni}$ recovery can be increased from 62 to 86 pct accordingly, but the $\mathrm{Ni}$ concentration in the $\gamma$ phase decreases from 10.5 to 4.8 mass pct. Therefore, the degree of sulfur deficiency should be optimized to achieve a relatively high degree of Ni recovery while having an acceptable $\mathrm{Ni}$ grade in the alloy.

The influence of temperature on the formation of various phases and on the recovery of $\mathrm{Ni}$ into the alloys (i.e., $\frac{\text { Mass of } \mathrm{Ni} \text { in alloys }}{\text { Mass of Ni in total }} \times 100 \mathrm{pct}$ ) was also evaluated, which is presented in Figure 3(b). As seen, with the increase of temperature in the range of $923 \mathrm{~K}$ to $1073 \mathrm{~K}$, alloy isomorphic phase transformation from $\alpha$ to $\gamma$ takes place, which also leads to an increase in the Ni recovery by approximately 10 pct. Temperatures higher than $1173 \mathrm{~K}$ lead to the formation of a Ni-bearing molten matte phase, which drastically reduces the formation of alloy phase(s) as well as Ni recovery. Therefore, the optimal temperature for Ni recovery into the alloy phase should be in the range of $1073 \mathrm{~K}$ to $1173 \mathrm{~K}$.

\section{B. Thermal Oxidation of Pyrr}

To allow the determination of an appropriate temperature for the partial oxidation of Pyrr, the oxidation reaction sequence of Pyrr was deduced based on TG/ DTA analysis. Figure 4 shows the TG, DTG, DTA, and offgas $\mathrm{SO}_{2}$ concentration plots against temperature. Occurrence of a thermal event would be reflected by the change in mass (TG or DTG) and/or heat flow (DTA). Determination of the nature of the thermal event can be

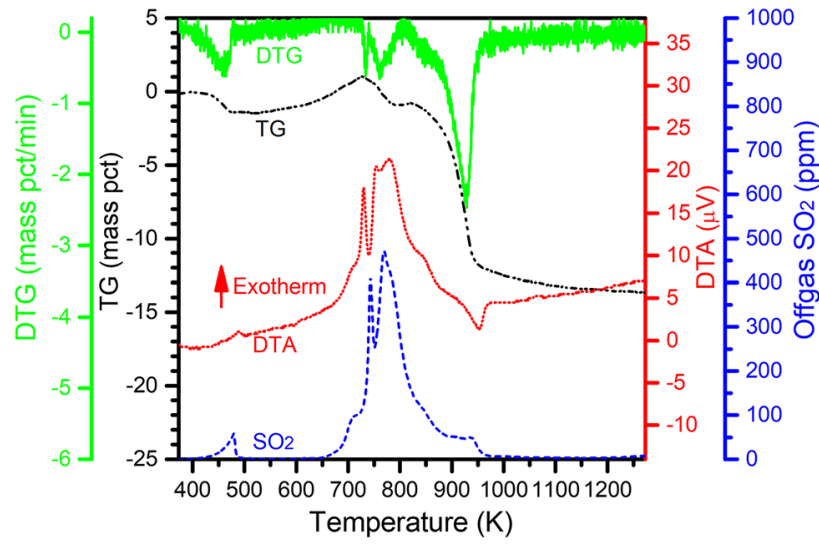

Fig. 4-TG/DTA and offgas analyses for the continuous heating of the Pyrr tailing at $10 \mathrm{~K} / \mathrm{min}$ in an air flow of $500 \mathrm{~mL} / \mathrm{min}$.

achieved by coupling the TG/DTA results with the analysis on the intermediate products collected before and right after the thermal event, using XRD (Figure 5) and SEM (Figure 6).

The first thermal event took place in the temperature range of $413 \mathrm{~K}$ to $474 \mathrm{~K}$, resulting in a slight mass loss by approximately 1.4 mass pct and $\mathrm{SO}_{2}$ evolution. DTA curve indicates that a corresponding exotherm took place at this temperature range. The XRD analysis on the intermediate product samples collected from $474 \mathrm{~K}$ (Figure 5) suggests the formation of $\varepsilon-\mathrm{Fe}_{2} \mathrm{O}_{3}$, which shows that this exotherm should be the surface oxidation of Pyrr, represented by Reaction [1] in Table II. Being one of the four polymorphs of iron (III) oxide, $\varepsilon$ $\mathrm{Fe}_{2} \mathrm{O}_{3}$ is orthorhombic with crystallographic group Pna2 $_{1}{ }^{[17]}$ This less common polymorph transformed into the more common $\alpha-\mathrm{Fe}_{2} \mathrm{O}_{3}$ (Reaction [2] in 


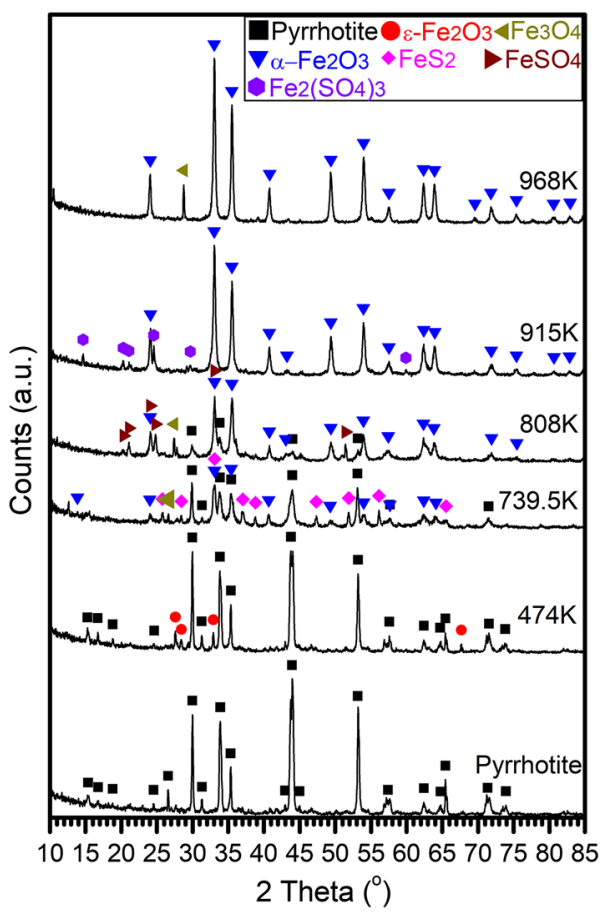

Fig. 5-XRD patterns for the Pyrr tailing and intermediate products collected from various temperatures.

Table II) in the temperature range of $474 \mathrm{~K}$ to $739 \mathrm{~K}$, based on the XRD results (Figure 5). In the temperature range of $474 \mathrm{~K}$ to $739 \mathrm{~K}$, a gradual mass gain took place, which was likely due to the occurrence of Reaction [3]. Considering this reaction is based on the presence of significant amounts of both $\alpha-\mathrm{Fe}_{2} \mathrm{O}_{3}$ and pyrite $\left(\mathrm{FeS}_{2}\right)$ in the intermediate products from $739.5 \mathrm{~K}$, as shown in Figures 5 and 6(c). A partially overlapped thermal event also took place, leading to the evolution of $\mathrm{SO}_{2}$ at temperatures higher than $653 \mathrm{~K}$. This exotherm is due to the oxidation of Pyrr forming $\alpha$ $\mathrm{Fe}_{2} \mathrm{O}_{3}$ (Reaction [4]). This reaction extended to temperatures as high as $915 \mathrm{~K}$, leading to the gradual development of a typical columnar structure of the formed $\mathrm{Fe}_{2} \mathrm{O}_{3}$ as shown in Figures 6(d) and (e). Formation of this characteristic columnar structure was due to the preferential inward oxidation along certain crystallographic planes. ${ }^{[18-20]}$ In the temperature range of $739 \mathrm{~K}$ to $808 \mathrm{~K}$, oxidation of $\mathrm{FeS}_{2}$ took place (i.e., Reaction [5]), evidenced by the disappearance of $\mathrm{FeS}_{2}$ peaks in the XRD pattern at $808 \mathrm{~K}$ (Figure 5), as well as the quick evolution of $\mathrm{SO}_{2}$ and mass loss in this temperature range as shown in Figure 4. The partial pressure of $\mathrm{SO}_{2}$ within the sample bed was high due to the quick evolution of $\mathrm{SO}_{2}$ in the temperature range of $739 \mathrm{~K}$ to $915 \mathrm{~K}$, which favored the formation of sulfates. ${ }^{[18]}$ As a result, a layer of $\mathrm{FeSO}_{4}$ or $\mathrm{Fe}_{2}\left(\mathrm{SO}_{4}\right)_{3}$ formed on the surface of partially oxidized Pyrr particles (Figures 6(d) and (e)), which can be represented by Reactions [6] and [7]. Thermal decomposition of the sulfate at $915 \mathrm{~K}$ to $968 \mathrm{~K}$ took place, leading to the quick mass loss (Figure 4) and disappearance of the sulfate phase at $968 \mathrm{~K}$ (Figures 5 and 6(f)).

\section{Sequential Partial Oxidation-Reduction of Pyrr}

From the study on the oxidation reaction sequence of Pyrr (Section III-B), it is seen that the principal oxidation reaction that leads to sulfur removal is Reaction [4], which spans over a wide temperature range from $653 \mathrm{~K}$ to $915 \mathrm{~K}$. Therefore, partial oxidation of Pyrr was performed at the temperature of $873 \mathrm{~K}$. After oxidation at $873 \mathrm{~K}$ for 25 seconds in the TGA unit, $\mathrm{Fe}_{2} \mathrm{O}_{3}$ having its characteristic columnar structure was formed in the outer portion of Pyrr particles, based on the SEM analysis. From the mass loss during oxidation, it was estimated that the degree of sulfur removal was approximately $35 \mathrm{pct}$.

The partial oxidation-reduction test (Test R1) was therefore performed by oxidation at $873 \mathrm{~K}$ for 25 seconds followed by $\mathrm{H}_{2}$ reduction at $1173 \mathrm{~K}$ for 7200 seconds (Figure 7). As seen from Figure 7, a quick mass loss took place after exposure to air at $873 \mathrm{~K}$, indicating an extremely high oxidation rate. Two distinct stages are apparent during reduction at 1173 $\mathrm{K}$ based on the TG curve. Lasting for approximately 150 seconds, the first stage is characteristic of a high reduction rate, reflected by the quick mass loss. This fast reduction stage should be the reduction of oxide that was formed during the initial oxidation step because $\mathrm{H}_{2}$ reduction of iron oxides is generally fast at $1173 \mathrm{~K} \cdot{ }^{[21]} \mathrm{In}$ contrast, the second stage exhibits a relatively linear and much slower mass loss rate. The mass loss reached 32.4 mass pct after reduction for 7200 seconds, representing approximately 79 pct sulfur removal. This means sulfur was further removed during the second reduction stage by about 44 pet, in addition to the 35 pet sulfur removal during the initial oxidation. This points to the direct reduction of sulfide by $\mathrm{H}_{2}$, i.e., Reaction [9]. The slow kinetics of the second reduction stage was possibly due to its small thermodynamic equilibrium constant $\left(K=4.2 \times 10^{-3}\right.$ at $\left.1173 \mathrm{~K}^{[16]}\right)$. According to Kor, ${ }^{[22]}$ the slow rate of hydrogen reduction of pyrrhotite at a temperature range of 873 to $1173 \mathrm{~K}$ was mainly controlled by the counter-current diffusion of $\mathrm{H}_{2}$ and $\mathrm{H}_{2} \mathrm{~S}$ in the gas-film boundary layer and in the porous iron layer. Figure 8 exhibits the cross section of the reduced product from Test R1, showing the presence of two major phases: alloy and sulfide. EDS point analysis along the arrow (Figure 8(b)) indicates that the $\mathrm{Ni}$ concentration in the sulfide phase was below the detection limit and that $\mathrm{Ni}$ became highly concentrated into the alloy phase. The mechanism that governs the migration of $\mathrm{Ni}$ into the alloy phase was the difference of the thermodynamic equilibrium $\mathrm{Ni}$ concentration in the sulfide $v s$ alloy phases. ${ }^{[14]}$ In the alloy region, Ni concentration was higher as it was further away from the sulfide/alloy boundary, up to 13 mass pct. Based on the observation, $\mathrm{Ni}$ can be successfully concentrated into the alloy during $\mathrm{H}_{2}$ reduction, allowing for further $\mathrm{Ni}$ recovery. However, due to the excessive reduction of sulfide by $\mathrm{H}_{2}$ (Reaction [9]), the mass ratio of alloy to sulfide in the product was approximately $2.4: 1$, resulting in a much lower average $\mathrm{Ni}$ grade of the alloy (i.e., the Ni concentration). 

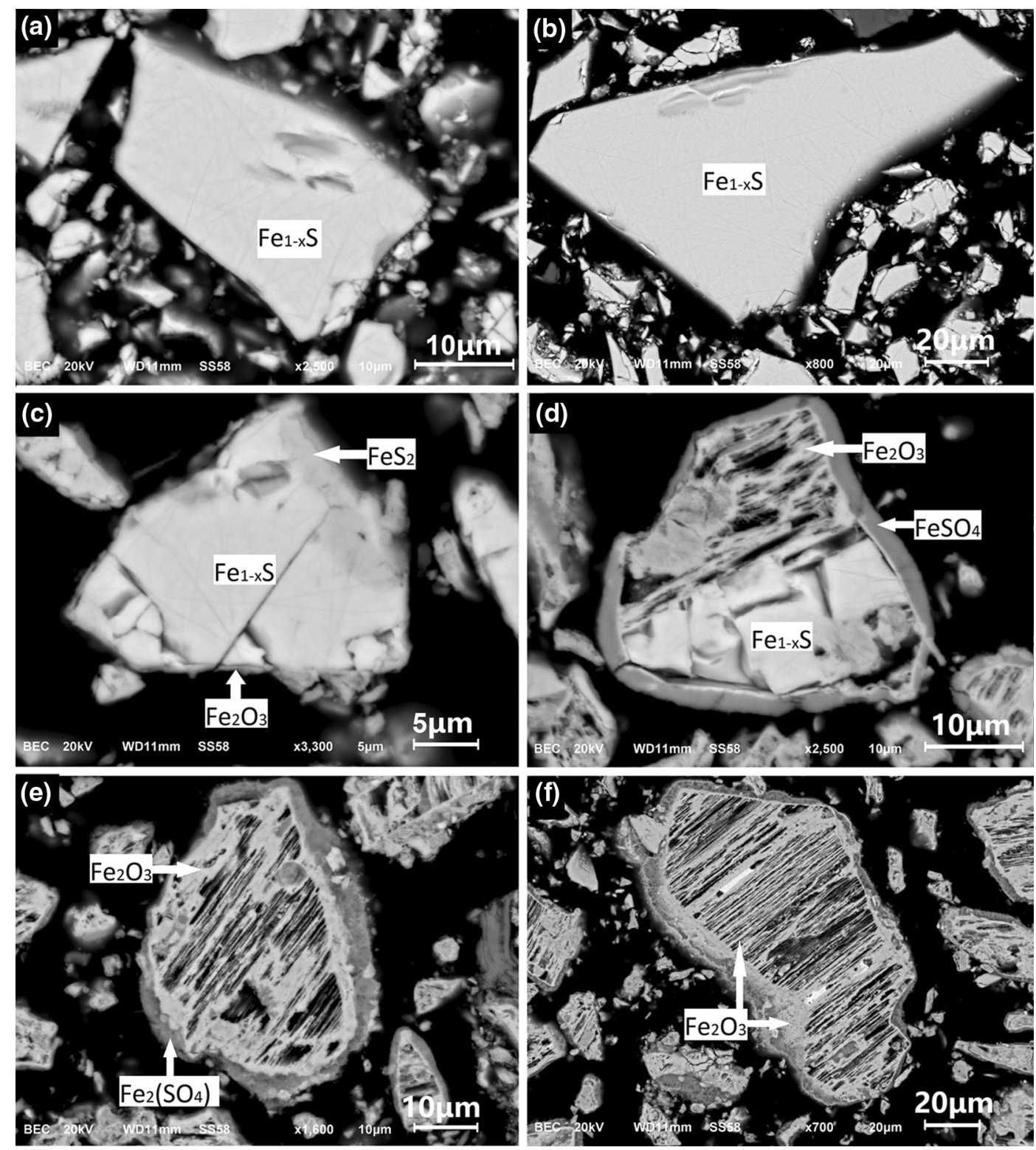

Fig. 6-Backscattered scanning electron (BSE) micrographs of the (a) Pyrr tailing and intermediate products collected from various temperatures (b: $474 \mathrm{~K} ; c: 739.5 \mathrm{~K} ; d: 808 \mathrm{~K} ; e: 915 \mathrm{~K} ; f: 968 \mathrm{~K})$.

Table II. Deduced Reaction Sequence During the Thermal Oxidation of Pyrr

\begin{tabular}{lll}
\hline Temperature Range & \multicolumn{1}{c}{ Reactions } & Reaction Number \\
\hline $413 \mathrm{~K}$ to $474 \mathrm{~K}$ & $2 \mathrm{Fe}_{1-x} \mathrm{~S}+(3.5-1.5 x) \mathrm{O}_{2}=(1-x) \varepsilon-\mathrm{Fe}_{2} \mathrm{O}_{3}+2 \mathrm{SO}_{2}$ & $(1)$ \\
$474 \mathrm{~K}$ to $739 \mathrm{~K}$ & $\varepsilon-\mathrm{Fe}_{2} \mathrm{O}_{3}=\alpha-\mathrm{Fe}_{2} \mathrm{O}_{3}$ & $(2)$ \\
$474 \mathrm{~K}$ to $739 \mathrm{~K}$ & $2 \mathrm{Fe}_{1-x} \mathrm{~S}+(0.75-1.5 x) \mathrm{O}_{2}=(0.5-x) \alpha-\mathrm{Fe}_{2} \mathrm{O}_{3}+\mathrm{FeS}_{2}$ & $(3)$ \\
$653 \mathrm{~K}$ to $915 \mathrm{~K}$ & $2 \mathrm{Fe}_{1-x} \mathrm{~S}+(3.5-1.5 x) \mathrm{O}_{2}=(1-x) \alpha-\mathrm{Fe}_{2} \mathrm{O}_{3}+2 \mathrm{SO}_{2}$ & $(4)$ \\
$739 \mathrm{~K}$ to $808 \mathrm{~K}$ & $2 \mathrm{FeS}_{2}+5.5 \mathrm{O}_{2}=\alpha-\mathrm{Fe}_{2} \mathrm{O}_{3}+4 \mathrm{SO}_{2}$ & $(5)$ \\
$739 \mathrm{~K}$ to $808 \mathrm{~K}$ & $\mathrm{Fe}_{1-x} \mathrm{~S}+(2-x) \mathrm{O}_{2}=(1-x) \mathrm{FeSO}_{4}+x \mathrm{SO}_{2}$ & $(6)$ \\
$808 \mathrm{~K}$ to $915 \mathrm{~K}$ & $2 \mathrm{FeSO}_{4}+\mathrm{SO}_{2}+\mathrm{O}_{2}=\mathrm{Fe}_{2}\left(\mathrm{SO}_{4}\right)_{3}$ & $(7)$ \\
$915 \mathrm{~K}$ to $968 \mathrm{~K}$ & $\mathrm{Fe}_{2}\left(\mathrm{SO}_{4}\right)_{3}=\alpha-\mathrm{Fe}_{2} \mathrm{O}_{3}+3 \mathrm{SO}_{2}+1.5 \mathrm{O}_{2}$ & $(8)$ \\
\hline
\end{tabular}


$\mathrm{FeS}+\mathrm{H}_{2}=\mathrm{Fe}+\mathrm{H}_{2} \mathrm{~S}(\Delta \mathrm{G}=53.4 \mathrm{~kJ} / \mathrm{mol}$ at $1173 \mathrm{~K})$

A second test (Test R2, Figure 7) was therefore performed by allowing the reduction stage for only 150 seconds, which prevented the remaining sulfide from the excessive $\mathrm{H}_{2}$ reduction, Reaction [9]. This resulted in a much lower alloy to sulfide mass ratio of the product, which was estimated to be 0.34:1. As seen from Figure 9(a), indeed much lower amounts of alloy phase were produced compared with Test R1 (Figure 8(a)). Essentially all alloy phases were intimately attached to the sulfide particles, enabling the possible $\mathrm{Ni}$ diffusion from sulfide to alloy. Figure $9 \mathrm{~b}$ exhibits a Pyrr particle with few alloy particles at the edge of sulfide, measuring $<10 \mu \mathrm{m}$. EDS point analysis along the arrow crossing the alloy/sulfide phase boundary is plotted in Figure 9(c). As seen, Ni concentration of the sulfide phase was lowered from an average 0.85 mass pct before thermal treatment to an undetectable level, and the alloy

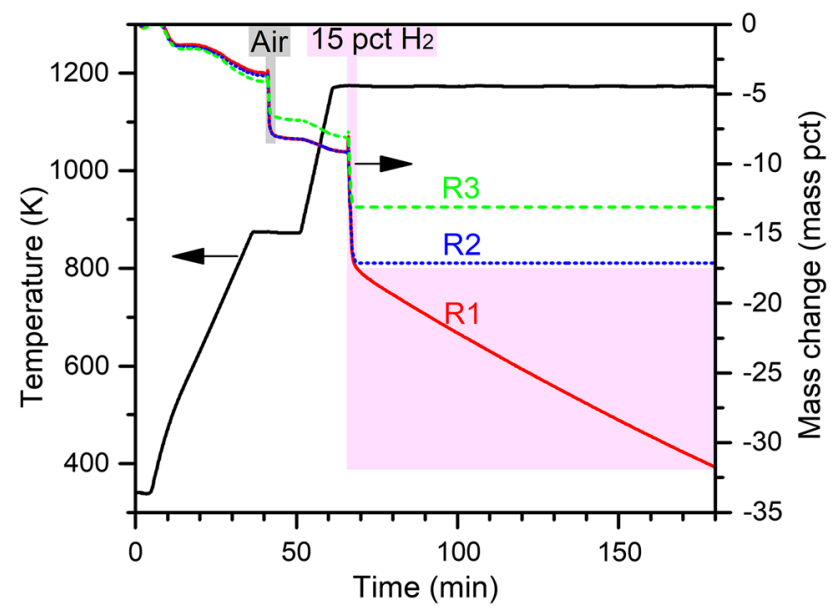

Fig. 7-TGA partial oxidation of Pyrr at $873 \mathrm{~K}$ followed by $\mathrm{H}_{2}$ reduction at $1173 \mathrm{~K}(\mathrm{R} 1$ : oxidation for $25 \mathrm{~s}$, reduction for $7200 \mathrm{~s}$; R2: oxidation for $25 \mathrm{~s}$, reduction for $150 \mathrm{~s}$; R3: oxidation for $15 \mathrm{~s}$, reduction for $116 \mathrm{~s})$.

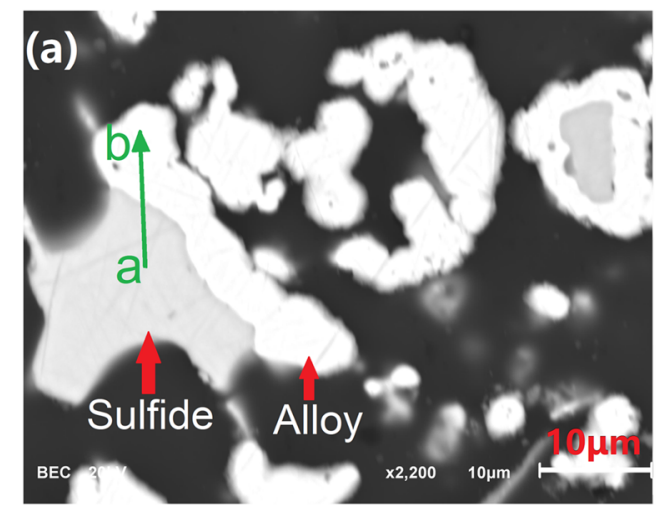

particles were highly concentrated with $\mathrm{Ni}$ with a concentration gradient from approximately 5 to 12 mass pct. Ni was therefore upgraded in the form of ferronickel alloy by a factor of about 10 .

A third thermal treatment test (Test R3) was also performed at an even smaller degree of sulfur removal by oxidation. As seen from Figure 7, oxidation was conducted for only 15 seconds, as opposed to $25 \mathrm{sec}-$ onds used for the other two tests. This resulted in a lower degree of sulfur removal at 23 mass pct, compared with 35 mass pet for Test R2. The amount of iron oxides produced apparently required a shorter time for subsequent reduction, which was about 116 seconds (Figure 7). Figures 9(d) through (g) illustrate the cross sectional micrograph of the product and its elemental mapping. Similarly, Ni became highly concentrated into the ferronickel alloy, demonstrating the effectiveness of the thermal treatment in terms of upgrading and recovery of $\mathrm{Ni}$.

\section{Thermal Treatment on Mixtures of Pyrr, Magnetite, and Petroleum Coke}

Pellet fragments composed of 68.2 mass pct Pyrr, 22.7 mass pct magnetite, and 9.1 mass pct petroleum coke were thermally treated in $\mathrm{Ar}$ at $1173 \mathrm{~K}$ for 30 minutes (Test T1). As seen from Figure 10, two $\mathrm{SO}_{2}$ peaks appeared in the temperature range of $473 \mathrm{~K}$ to $973 \mathrm{~K}$, leading to a mass loss of approximately 4 mass pet. This was likely resulting from the reaction(s) between Pyrr and magnetite. Reduction of magnetite by petroleum coke (Reactions [10] and [11]) took place at temperatures above $973 \mathrm{~K}$, evidenced by the evolution of both $\mathrm{CO}$ and $\mathrm{CO}_{2}$ gases and its corresponding mass loss. SEM analysis of the thermally treated product (Figure 11) revealed the formation of ferronickel alloy particles with sizes smaller than $10 \mu \mathrm{m}$. EDS analysis on selected alloy particles indicates the presence of 13 to 21 mass pct $\mathrm{Ni}$, owing to the $\mathrm{Ni}$ diffusion from the nickeliferous sulfide to the newly formed metallic Fe by the reduction of magnetite. However, the sulfide phase still contained 0.35 to 0.45 mass pet $\mathrm{Ni}$, indicating that

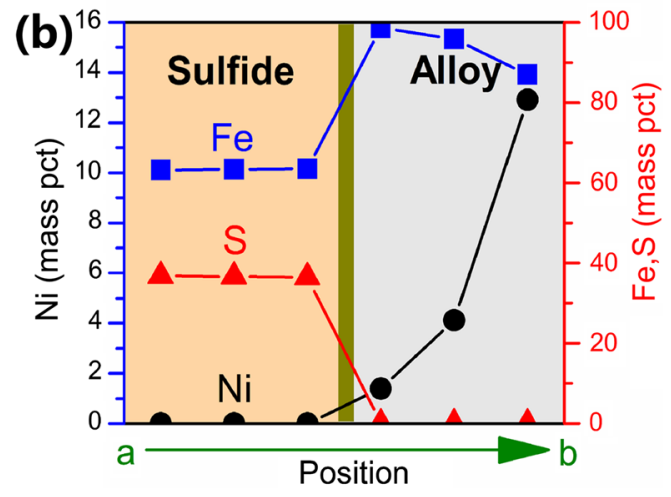

Fig. 8- (a) BSE micrograph of the reduced product from Test R1, and (b) EDS point analysis along the arrow a $\rightarrow$ b. 


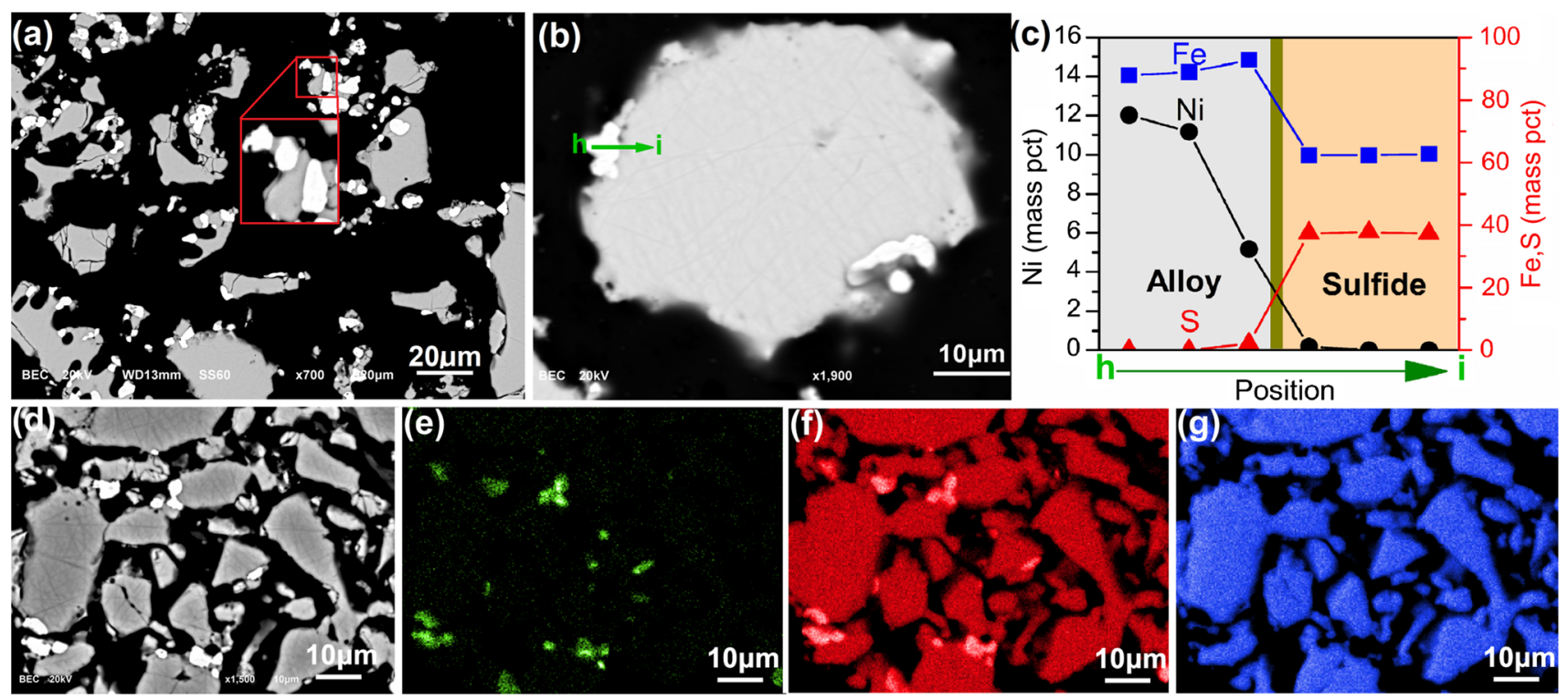

Fig. 9- $(a, b)$ BSE micrographs of the reduced product from Test R2 and (c) EDS point analysis along the arrow $\mathrm{h} \rightarrow \mathrm{i} ;(d)$ BSE micrograph of the reduced product from Test $\mathrm{R} 3$, and its elemental mapping of $(e) \mathrm{Ni},(f) \mathrm{Fe}$, and $(g) \mathrm{S}$.

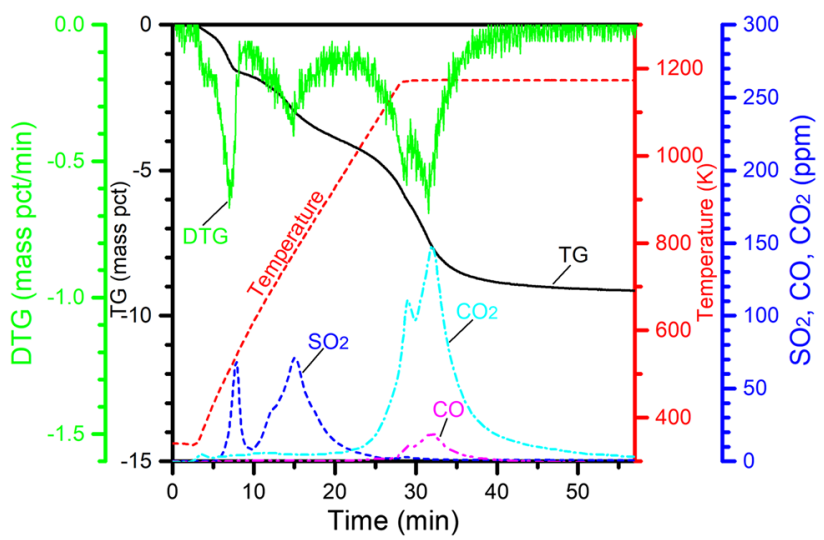

Fig. 10-TG/DTA and offgas analyses on the thermal treatment of pellet fragments composed of Pyrr, magnetite, and petroleum coke (Test T1).

the distribution of $\mathrm{Ni}$ between the sulfide and alloy was still not close to equilibrium. The combination of a few factors should have contributed to the deviation from equilibrium. First of all, magnetite and petroleum coke particles must have an initially reasonable contact before magnetite could be reduced directly by petroleum coke (Reactions [10] and [11]). Although it was attempted to provide such conditions by using extremely fine powders and compacting the powders into pellet, solid-solid reactions are still slow due to inadequate contact in atomic scale. The reaction is accelerated in the presence of reducing gases involving the reduction of magnetite by $\mathrm{CO}$ (i.e., Reaction [12]) and regeneration of $\mathrm{CO}$ by the Boudouard reaction (i.e., Reaction [13]). ${ }^{[23]}$ However, the Pyrr particles within the pellets act as barriers that hinder the solid and gaseous reduction of Pyrr to a certain degree. For example, $\mathrm{RaO}^{[24]}$ found that the presence of FeS inhibited the reduction of $\mathrm{Fe}_{2} \mathrm{O}_{3}$ by carbon. It was claimed that the
$\mathrm{SO}_{2}$ gas generated would compete with $\mathrm{CO}_{2}$ for available reaction sites on the carbon surface (Reaction [13]), thereby retarding the Boudouard reaction. Resulting from the complex reduction mechanism, nucleation and growth of the metallic $\mathrm{Fe}$ particles and their spatial distribution within the sample pellet must allow for effective Ni diffusion from Pyrr particles to their most adjacent Fe particles. Uneven distribution of the newly formed $\mathrm{Fe}$ particles within the pellet and their poor physical contact with Pyrr particles would increase the average length of the $\mathrm{Ni}$ diffusion path, requiring a longer time for Ni migration into the metallic phase. As seen from Figure 11, the presence of residual petroleum coke particles also acted as a physical barrier to hinder effective Ni diffusion. Due to these factors, dwelling at $1173 \mathrm{~K}$ for 30 minutes as shown in Figure 10 was likely not long enough to allow for sufficient extraction of $\mathrm{Ni}$ into the metallic phase.

$$
\begin{gathered}
\mathrm{Fe}_{3} \mathrm{O}_{4}+2 \mathrm{C}=3 \mathrm{Fe}+2 \mathrm{CO}_{2} \\
\mathrm{Fe}_{3} \mathrm{O}_{4}+4 \mathrm{C}=3 \mathrm{Fe}+4 \mathrm{CO} \\
\mathrm{Fe}_{3} \mathrm{O}_{4}+4 \mathrm{CO}=3 \mathrm{Fe}+4 \mathrm{CO}_{2} \\
\mathrm{CO}_{2}+\mathrm{C}=2 \mathrm{CO}
\end{gathered}
$$

The ferronickel alloy particles formed after the thermal treatment will need to be subsequently physically liberated from their associated sulfide to allow for their separation. As seen from all tests discussed above, essentially most of the alloy particles formed were smaller than $10 \mu \mathrm{m}$, imposing a significant challenge in their liberation and subsequent separation. Therefore, 


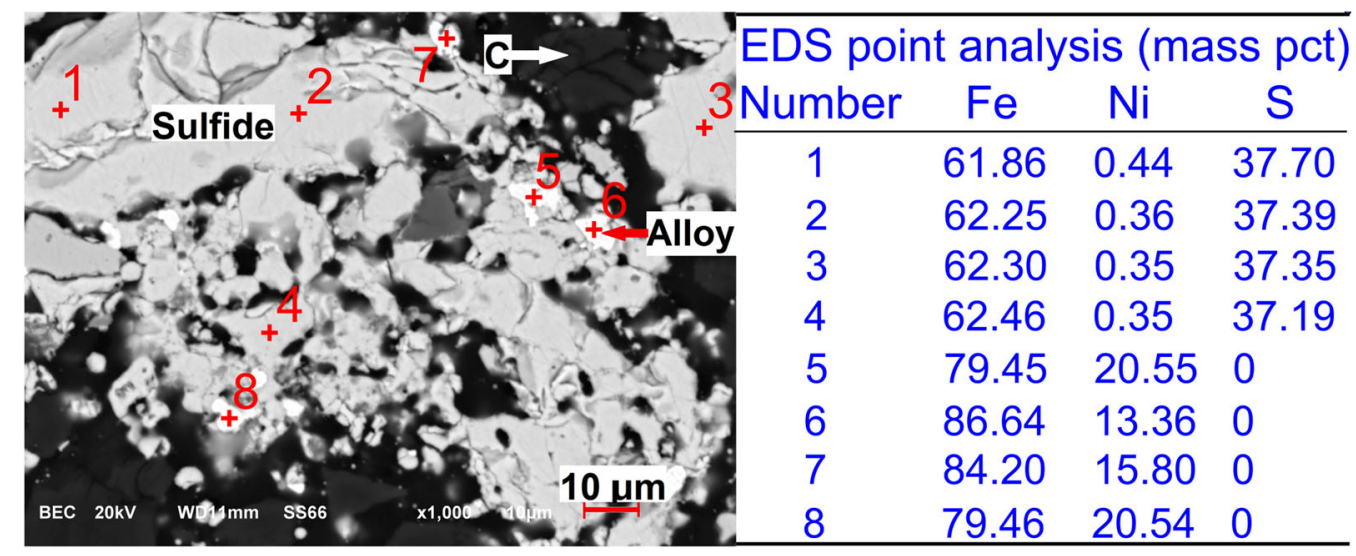

Fig. 11-BSE micrograph of the thermally treated product from Test T1 and EDS point analysis on sulfide and alloy phases.

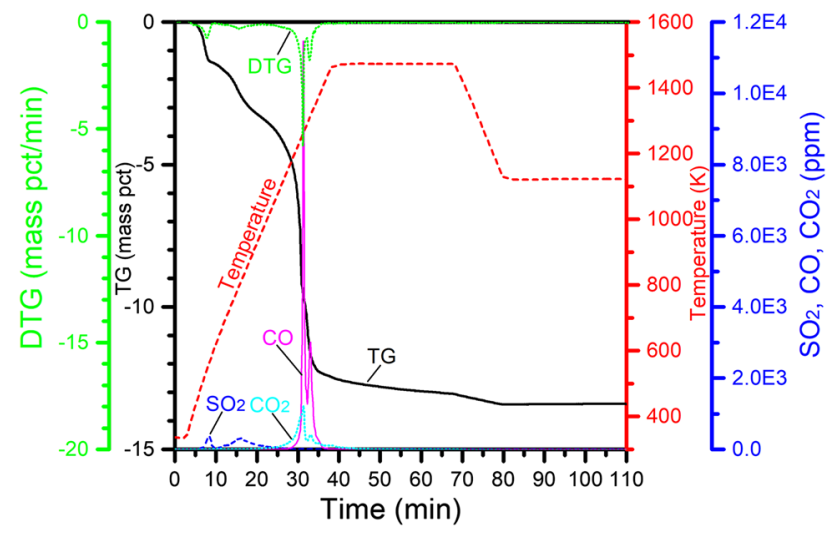

Fig. 12-TG/DTA and offgas analyses on the thermal treatment of the mixture of Pyrr, magnetite, and petroleum coke in an $\mathrm{Ar}$ atmosphere (Test T2).

growth of the ferronickel alloy is the second focus of the study. One approach was proposed by taking advantage of the thermodynamics as illustrated in Figure 3(b). As seen, temperatures higher than $1373 \mathrm{~K}$ would lead to the formation of 100 pct molten matte phase. It can be depicted that the solid $\gamma$ alloy phase would precipitate from the molten matte upon cooling, during which the growth of the alloy particles is expected. For this purpose, Test T2 (Figure 12) was conducted by heating the mixture $(150 \mathrm{mg})$ of 68.2 mass pet Pyrr, 22.7 mass pct magnetite, and 9.1 mass pet petroleum coke to $1473 \mathrm{~K}$ and dwelling for 30 minutes. It was then cooled at a rate of $30 \mathrm{~K} / \mathrm{min}$ to $1123 \mathrm{~K}$, followed by holding for another 30 minutes to allow for complete solidification of the melt before cooling further to room temperature. As seen, reduction of magnetite (Reactions [10] through [12]) took place resulting in the evolution of $\mathrm{CO}$ and $\mathrm{CO}_{2}$ and its corresponding mass loss, forming metallic Fe. Upon heating to $1473 \mathrm{~K}$, the metallic Fe would be dissolved to form a complete molten matte. Examination of the solidified product (Figure 13) revealed the precipitation of ferronickel alloy particles that were embedded in the sulfide matrix. Quantification

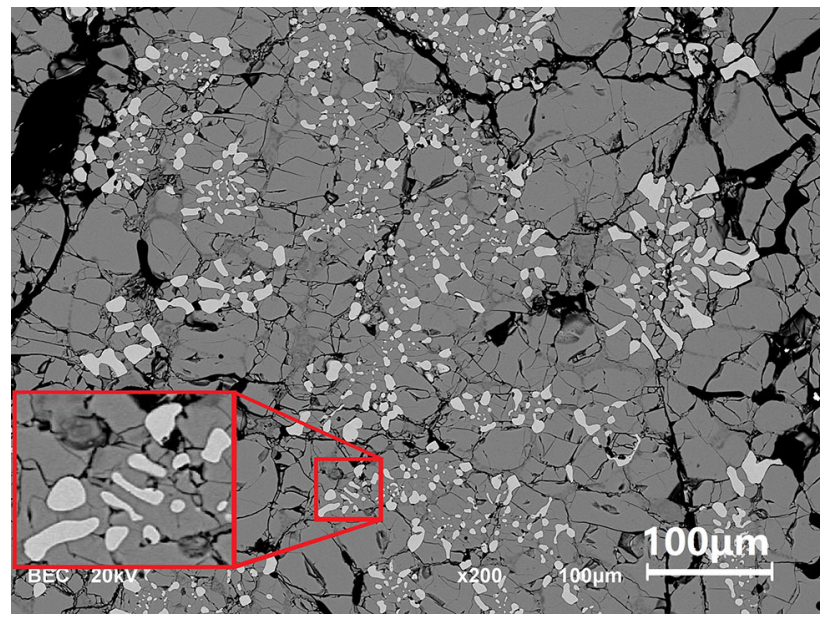

Fig. 13-BSE micrograph of the thermally treated product from Test T2.

of the size distribution of alloy particles was performed by analyzing the SEM images using the image analysis software ImageJ, ${ }^{[25]}$ which was plotted in Figure 14. For comparison, the particle size distribution of alloys produced from Test R2 was also plotted. As seen, precipitation of alloys from the molten matte can effectively increase their particle sizes, with a median particle size (i.e., $d(0.5))$ of $13 \mu \mathrm{m}$, compared with that of $7 \mu \mathrm{m}$ for Test R2.

To increase the alloy particle sizes during thermal treatment further, attempts were made by employing a much larger sample size and a slower cooling rate for alloy precipitation. The reason is that a slower cooling rate would allow a longer time for the growth of ferronickel alloy particles in the molten matte. In addition, given a low enough viscosity of the molten matte, the newly formed alloy particles would settle slowly toward the bottom of the melt, due to the density difference between the ferronickel alloy and the molten matte. A slower cooling rate would allow a longer time for the settling of alloy. Further growth of the alloy 


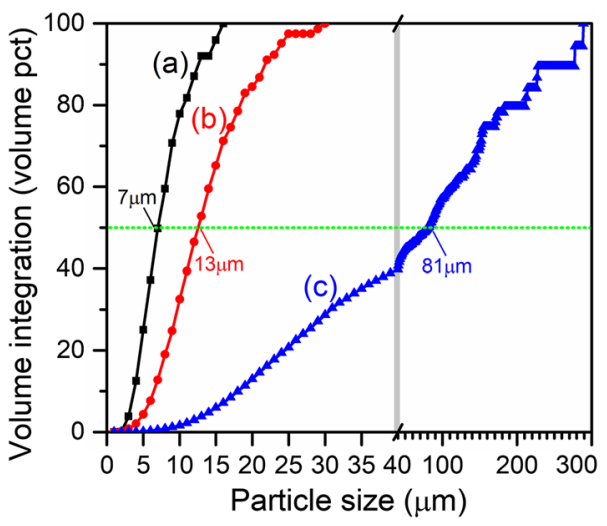

Fig. 14 - Size distribution of the alloy particles formed from $(a)$ Test R2, (b) Test T2, and (c) Test T3. (The vertical line indicates the change in the scale of $x$-axis.).

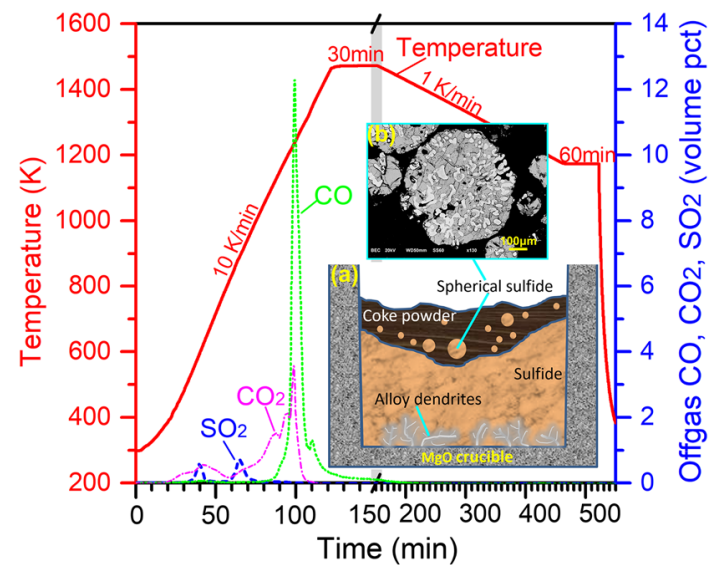

Fig. 15-Temperature profile and offgas analysis in Test T3 (thermal treatment of the mixture of Pyrr, magnetite, and petroleum coke). Inset (a) schematically illustrates the vertical cross section of the product, and (b) BSE micrograph shows the spherical sulfide particles embedded within the petroleum coke powder bed. particles can be expected at the bottom of the melt due to the presence of a higher population of settled alloy particles that can merge and form larger particles. The population of settled alloy particles can be further increased by using a larger sample size and having a greater depth of the melt. Test T3 was therefore performed by heating $7 \mathrm{~g}$ of the mixture of 68.2 mass pct Pyrr, 22.7 mass pct magnetite, and 9.1 mass pct petroleum coke (placed in a $\mathrm{MgO}$ crucible, inner diameter $1.5 \mathrm{~cm}$ ) inside a vertical tube furnace with continuous purging of Ar at $500 \mathrm{~mL} / \mathrm{min}$. The temperature profile is plotted in Figure 15 along with the offgas $\mathrm{CO}, \mathrm{CO}_{2}$, and $\mathrm{SO}_{2}$ concentrations. Similar to Tests $\mathrm{T} 1$ and $\mathrm{T} 2$, reduction of magnetite by petroleum coke resulted in the evolution of $\mathrm{CO}$ and $\mathrm{CO}_{2}$, forming metallic Fe. On holding at $1473 \mathrm{~K}$ for 30 minutes, a complete molten matte would form, followed by slow cooling at a rate of $1 \mathrm{~K} / \mathrm{min}$ to $1173 \mathrm{~K}$. It was then held at $1173 \mathrm{~K}$ for 60 minutes to ensure complete solidification before cooling to room temperature. Figure 15(a) schematically illustrates the vertical cross section of the sample product, measuring a total sample depth of approximately $6 \mathrm{~mm}$. Residual petroleum coke powders in the sample mixture floated to the top after the sulfide became completely molten, during which some sulfide was dragged upward and became entrained and suspended in the petroleum coke powder bed as spherical sulfide particles (Figure 15(b)). As expected, relatively large dendritic alloy particles indeed formed at the bottom of the melt (Figures 15(a) and 16(a) and (b)). This was due to the coalescence of smaller alloy particles that settled to the bottom of melt during slow cooling, as discussed above. Precipitation of smaller alloy particles can be found uniformly throughout the sample cross section, as shown in Figure 16(c). These secondary particles could originate from precipitation just before solidification (so they cannot grow too large) or solidstate diffusion afterward. Likely it is a combination of both of these. The size distribution of the alloy particles

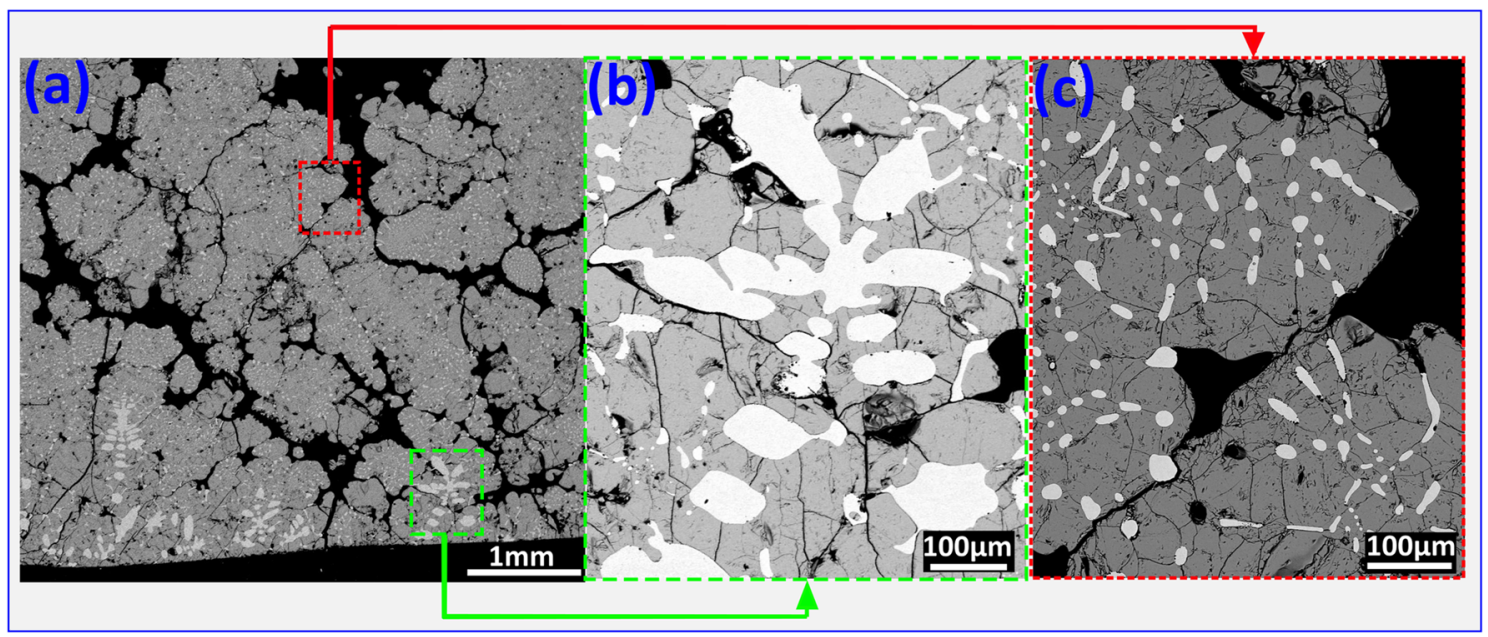

Fig. 16-BSE micrograph $(a)$ of the vertical cross section of the solidified product from Test T3, showing the formation of large dendritic alloy particles $(b)$ at the bottom, and precipitation of smaller alloy particles in other areas $(c)$. 
was also analyzed and plotted in Figure 14 for comparison. It is apparent that the growth of ferronickel alloy particles was enhanced significantly, having a median particle size of $81 \mu \mathrm{m}$. This demonstrates the effectiveness in promoting alloy growth by the approach of alloy settling, facilitating subsequent liberation of alloys for further upgrading.

\section{CONCLUSION}

Thermal upgrading of nickeliferous Pyrr tailings for the recovery of $\mathrm{Ni}$ in the form of ferronickel alloy was studied by both thermodynamic evaluation and experimentation. Two thermal upgrading approaches were investigated experimentally: (a) partial oxidation of Pyrr by air for the partial removal of sulfur followed by $\mathrm{H}_{2}$ reduction; and (b) generation of metallic Fe from the reduction of magnetite by petroleum coke powders that were premixed with Pyrr.

(1) Thermodynamic assessment demonstrates the possible high $\mathrm{Ni}$ recovery in the form of ferronickel alloys at a temperature range of $1073 \mathrm{~K}$ to $1173 \mathrm{~K}$ by lowering the sulfur-to-metal ratio.

(2) Study on the oxidation of Pyrr by air revealed the oxidation reactions spanned over a wide temperature range of $413 \mathrm{~K}$ to $968 \mathrm{~K}$. The main reaction that led to sulfur removal took place in the temperature range of $653 \mathrm{~K}$ to $915 \mathrm{~K}$, forming gaseous $\mathrm{SO}_{2}$ and hematite $\left(\alpha-\mathrm{Fe}_{2} \mathrm{O}_{3}\right)$ with its characteristic columnar structure. Other side reactions include the formation of $\mathrm{FeS}_{2}$ at $474 \mathrm{~K}$ to $739 \mathrm{~K}$, oxidation of $\mathrm{FeS}_{2}$ at $739 \mathrm{~K}$ to $808 \mathrm{~K}$, formation of sulfates at 739 $\mathrm{K}$ to $915 \mathrm{~K}$, etc.

(3) In the first thermal upgrading approach, both partial oxidation $(873 \mathrm{~K})$ and reduction $(1173 \mathrm{~K})$ were kinetically fast, taking no more than 25 and 150 seconds, respectively. $\mathrm{Ni}$ could be effectively concentrated in the small ferronickel alloy particles $(<10 \mu \mathrm{m})$ that were intimately attached to the sulfide particles. It was also found that $\mathrm{FeS}$ could also be directly reduced by $\mathrm{H}_{2}$ at $1173 \mathrm{~K}$ forming metallic Fe but at a much slower rate.

(4) In the second thermal upgrading approach, reduction of magnetite by petroleum coke occurred at temperatures above $973 \mathrm{~K}$. Driven by the solubility difference of $\mathrm{Ni}$ in metallic Fe vs sulfide phases under thermodynamic equilibrium conditions, diffusion of $\mathrm{Ni}$ from the nickeliferous sulfide to the newly formed metallic Fe took place, resulting in the formation of ferronickel alloy with a $\mathrm{Ni}$ concentration of 13 to 21 mass pct.

(5) A sulfur-deficient molten matte phase could form by thermal treatment at a higher temperature of 1473
K. Slow cooling of the molten matte resulted in precipitation and gradual settling of the alloy particles to the bottom of the melt. Relatively large dendritic ferronickel alloy particles could form by recrystallization of the settled alloy particles, thereby significantly increasing the overall alloy particle sizes.

\section{REFERENCES}

1. E. Peek, A. Barnes, and A. Tuzun: Miner. Eng., 2011, vol. 24, pp. 625-37.

2. P.F. Wells, S. Kelebek, M.J. Burrows, and D.F. Suarez: In J.A. Finch, S.R. Rao, and I. Holubec (Eds.), In Proc. UBC-McGill BiAnnu. Int. Symp. Fundam. Miner. Process., Sudbury, Ontario, Canada, 1997, pp. 51-62.

3. S. Garg, K. Judd, R. Mahadevan, E. Edwards, and V.G. Papangelakis: Can. Metall. Q., 2017, vol. 56, pp. 372-81.

4. S. Rezaei, F. Liu, S. Marcuson, M. Muinonen, V.L. Lakshmanan, R. Sridhar, and M. Barati: Can. Metall. Q., 2017, vol. 56, pp. 41017.

5. L.N. Ertzeva, L.S. Tzemekhman, and V.T. Diachenko: In Sohn Int. Symp. Adv. Process. Met. Mater. Vol. 8 -Int. Symp. Sulfide Smelt., 2006, vol. 8, pp. 419-21.

6. L.N. Ertzeva, L.S. Tzemekhman, and V.T. Diachenko: In Sohn Int. Symp. Adv. Process. Met. Mater. Vol. 4 - New, Improv. Exist. Technol.: Non-ferr. Mater. Extr. Process. 2006, vol. 4, pp. 385-87.

7. T. Deng: Int. J. Miner. Process., 1995, vol. 43 (1-2), pp. 91-98.

8. H. Liu: In EMC '91, Non-ferr. Metall. - Present Future, 1991, pp. 157-63.

9. J. Gast: Inco Triangle., 1991, vol. 50, p. 5.

10. G. Tremblay: In Proc. Int. Counc. Met. Environ. (ICME), 1998, pp. 32-33.

11. M.R. Gunsinger, C.J. Ptacek, D.W. Blowes, and J.L. Jambor: $J$. Contam. Hydrol., 2006, vol. 83, pp. 149-70.

12. A. Illis and L.S. Renzoni: Canadian Patent CA155032, 1972.

13. R. Sridhar, A. Dalvi, H.F. Bakker, and A. Illis: Can. Metall. Q., 1976, vol. 15, pp. 255-62.

14. F. Liu, D. Yu, S. Marcuson, F. Wang, B. Li, and M. Barati: Miner. Eng., 2019, vol. 134, pp. 206-14.

15. R. Cameron, B. Yu, C. Baxter, A. Plugatyr, R. Lastra, M. DalCin, P.H.J. Mercier, and N. Perreault: Extraction, 2018, vol. 2018, pp. 2669-79.

16. C.W. Bale, E. Bélisle, P. Chartrand, S.A. Decterov, G. Eriksson, A.E. Gheribi, K. Hack, I.H. Jung, Y.B. Kang, J. Melançon, A.D. Pelton, S. Petersen, C. Robelin, J. Sangster, P. Spencer, and M.A. Van Ende: Calphad, 2016, vol. 54, pp. 35-53.

17. R. Zboril: Chem. Mater., 2002, vol. 14, pp. 969-82.

18. D. $\mathrm{Yu}$ and T.A. Utigard: Thermochim. Acta, 2012, vol. 533, pp. 56-65.

19. P.G. Thornhill and L.M. Pidgeon: JOM, 1957, vol. 9, pp. 989-95.

20. M. Zamalloa and T.A. Utigard: Can. Metall. Quart., 1996, vol. 35, pp. $435-49$.

21. D. Yu, M. Zhu, T.A. Utigard, and M. Barati: Miner. Eng., 2013, vol. 54, pp. 32-38

22. G.J.W. Kor: Metall. Trans., 1974, vol. 5, pp. 339-43.

23. M.O. Boudouard: Ann. Chim. Phys., 1901, vol. 24, pp. 1-85.

24. Y.K. Rao: Metall. Trans., 1971, vol. 2, pp. 1439-47.

25. A.C. Schneider, W.S. Rasband, and K.W. Eliceiri: Nat. Methods, 2012, vol. 9, pp. 671-75.

Publisher's Note Springer Nature remains neutral with regard to jurisdictional claims in published maps and institutional affiliations. 